Article

\title{
Comparative Analysis of Power Plant Options for Enhanced Geothermal Systems (EGS)
}

\author{
Mengying Li and Noam Lior * \\ Department of Mechanical Engineering and Applied Mechanics, University of Pennsylvania, \\ Philadelphia, PA 19104-6315, USA; E-Mail: limengying2011@gmail.com \\ * Author to whom correspondence should be addressed; E-Mail: lior@seas.upenn.edu; \\ Tel.: +1-215-898-4803.
}

External Editor: Ron Zevenhoven

Received: 31 October 2014; in revised form: 2 December 2014 / Accepted: 10 December 2014 / Published: 17 December 2014

\begin{abstract}
Enhanced geothermal systems (EGS) extract heat from underground hot dry rock (HDR) by first fracturing the HDR and then circulating a geofluid (typically water) into it and bringing the heated geofluid to a power plant to generate electricity. This study focuses on analysis, examination, and comparison of leading geothermal power plant configurations with a geofluid temperature from 200 to $800{ }^{\circ} \mathrm{C}$, and also analyzes the embodied energy of EGS surface power plants. The power generation analysis is focused on flash type cycles for using subcritical geofluid $\left(<374{ }^{\circ} \mathrm{C}\right)$ and expansion type cycles for using supercritical geofluid $\left(>374^{\circ} \mathrm{C}\right)$. Key findings of this study include: (i) double-flash plants have $24.3 \%-29.0 \%$ higher geofluid effectiveness than single-flash ones, and $3 \%-10 \%$ lower specific embodied energy; (ii) the expansion type plants have geofluid effectiveness $>750 \mathrm{~kJ} / \mathrm{kg}$, significantly higher than flash type plants (geofluid effectiveness $<300 \mathrm{~kJ} / \mathrm{kg}$ ) and the specific embodied energy is lower; (iii) to increase the turbine outlet vapor fraction from 0.75 to 0.90 , we include superheating by geofluid but that reduces the geofluid effectiveness by $28.3 \%$; (iv) for geofluid temperatures above $650{ }^{\circ} \mathrm{C}$, double-expansion plants have a $2 \%$ higher geofluid effectiveness and $5 \%-8 \%$ lower specific embodied energy than single-expansion ones.
\end{abstract}

Keywords: engineered geothermal system (EGS); flash type power plants; expansion type power plants; plant utilization efficiency; geofluid effectiveness; plant embodied energy 


\section{Introduction and Objectives}

Geothermal energy is abundant, with a long term potential estimated to be more than 200,000-fold the current world energy demand [1] if hot dry rock resources at a depth of $10 \mathrm{~km}$ or more would become economically accessible. It is usually available at a steady supply rate and is thus much more usable than the intermittent and unsteady wind and solar [2]. Up to the year 2010, the total installed capacity of geothermal power plants worldwide was 10,898 MW, corresponding to about $67.25 \mathrm{TWh}$ of electricity with an average plant capacity factor of 70.4\% [3]. The forecast for 2015 is $140 \mathrm{TWh} / \mathrm{year}$ and the expected minimum by 2050 will be $1200 \mathrm{TWh} /$ year [3].

Geothermal resources exist mainly in two categories: convection dominant and conduction dominant. A convection dominant resource, also called natural hydrothermal system, contains sufficient natural hot fluid that can be brought directly to the surface for electricity generation. A conduction dominant resource does not have natural fluid and the heat is contained in hot dry rock (HDR), with the systems designed to use HDR resources are called engineered or enhanced geothermal systems (EGS). A typical EGS contains three parts, injection and production wells, engineered reservoir and a surface power plant. EGS system requires circulating water (geofluid) between the surface-located power plant and the underground engineered reservoir, where the geofluid is heated in the reservoir by its passage through the surrounding hot rocks and brought back to the surface power plant to generate electricity.

All current commercial geothermal power plants are from hydrothermal resources, while plants based on essentially dry hot rock reservoirs are expected to be commercial in the future. The growth rates of geothermal energy usage over many regions have been over $10 \%$ per year [3] and the geothermal exploitation techniques and understandings of the geothermal reservoirs are developing rapidly over the past decade or two.

The geothermal gradient (temperature rise with depth) of HDR resource typically ranges between 10 and $100{ }^{\circ} \mathrm{C} / \mathrm{km}$ [4]. In the continental US within the depth of $10 \mathrm{~km}$, more than $99 \%$ of the geothermal energy is contained in hot rocks [1]. Aiming at HDR resource to the depths of $10 \mathrm{~km}$, the geofluid temperatures are $100-800{ }^{\circ} \mathrm{C}$, thus having a very high power generation potential that increases with depth. In EGS it is generally recommended that the geofluid be kept and sent to the power plant in liquid or supercritical phase, rather than in the vapor phase [1,2,5]. Consequently, EGS power plants in this temperature range are configured to use liquid/supercritical geofluid.

A brief review of most common designs for EGS power system is presented below. More in-depth discussion of the design, unit processes, usage and optimizations of these systems can be found in $[1,2,6-12]$ and some other sources. There are generally three basic configurations of power plants could be used in EGS power generation:

1. Flash-type, including single-flash, double-flash and multiple-flash. In flash type plants, the liquid phase geofluid is flash-evaporated to a lower pressure to generate vapor for power generation. Flash-type is often applied when the geofluid exceeds $150{ }^{\circ} \mathrm{C}$ [2]. The higher the temperature of the geofluid, the more flash steps could be applied to improve the power plant's overall thermodynamic efficiencies. However, the system and its operation and maintenance complexity increase with the number of flash stages, so, double-flash is commonly used for high temperature resources $\left(>250^{\circ} \mathrm{C}\right)[2]$. 
2. Binary-type, which are widely used in extracting thermal energy from low and moderate grades geothermal resource (usually below $150{ }^{\circ} \mathrm{C}$ ), when direct flashing the geofluid is undesired. The limit could rise to $200{ }^{\circ} \mathrm{C}$ by selecting proper secondary fluid $[4,13]$. The basic idea of binary cycles is to use a different fluid as the cycle working fluid, heated up to evaporate by the geothermal fluid in evaporator, and produce work by its flow through a turbine. The steam exhaust from the turbine is then condensed by a condenser and returned to the evaporator in a closed loop. The secondary fluid is chosen to be compatible in many ways with the geofluid temperature so as to yield optimized system thermodynamic and economic performance. Secondary fluids include hydrocarbons, chlorofluorocarbons and ammonia. The criteria for working fluid choice include heat transfer and thermodynamic performance, flammability (hydrocarbons are highly flammable), impact on the environment (chlorofluorocarbons deplete ozone and have strong global warming potential), and turbine erosion potential due to expansion into the mixed liquid-vapor phase region [12,14-20].

3. Expansion-type, including triple, double, or single expansion. Such cycles are used to convert the thermal energy from supercritical geofluid to power [1]. The supercritical geofluid expands in a super pressure turbine (SPT) to generate electricity. Exhausted geofluid from SPT are separated into vapor and liquid, where vapor could generate electricity in a lower pressure turbine and liquid could flash to generate electricity as in flash-type plant.

The main objective of this work is to compare leading geothermal power plant configurations and to propose most suitable plant configurations for mid-high grade [21,22] deep HDR resources where the geofluid temperature ranges from 200 to $800{ }^{\circ} \mathrm{C}$. Single-flash and double-flash cycles are studied for electricity generation using subcritical geofluid $\left(<374{ }^{\circ} \mathrm{C}\right)$ and triple-expansion, double-expansion and single-expansion cycles are chosen for using supercritical geofluid $\left(>374{ }^{\circ} \mathrm{C}\right)$.

\section{Methodology}

The analysis is by simulation, using ASPEN PLUS software [23]. The results are aimed at sensitivity analysis of main criteria of system performance to power plant configuration and operating conditions (such as the geofluid temperature), with an ultimate objective to select best plant configurations for particular operating conditions.

Air-cooled condensers are used in the analyzed systems, and water-cooled condensers using an evaporative cooling tower are simulated for comparison as described in Section 3.4. In our simulation, air-cooled condensers are modeled with the ASPEN PLUS build-in block "Heat Exchanger".

Water injected into an EGS reservoir often picks up various minerals and gases. A thorough analysis should include their effects on evaporation, condensation and scale formation. The associated complexity that is associated with their consideration in system analysis, accompanied by insufficient experimental information on their amount in various EGS systems, and the fact that typically their content in the geofluid is much lower in EGS than in hydrothermal geothermal fluids, led most of the past published studies that present calculations of EGS power output to assume that the geofluid is pure $[1,7,9-11,24]$, and we have similarly assumed in this study that the EGS geofluid is pure water devoid of gases and minerals. 


\subsection{The System Performance Criteria}

To evaluate the overall performance of geothermal power cycles, we define the plant "utilization efficiency" $\eta_{\mathrm{U}}$, which measures the extent to which the available exergy of the geofluid is put to practical use [25], as:

$$
\eta_{\mathrm{U}}=\frac{\dot{W}_{\text {net }}}{\dot{E}_{\mathrm{gf} \_ \text {in }}}=\frac{\dot{W}_{\text {turbine }} \eta_{\mathrm{g}}-\dot{W}_{\text {parasitic }}}{\dot{m}_{\mathrm{gf} \_ \text {in }} e_{\mathrm{gf} \_ \text {in }}}
$$

where:

$\dot{W}_{\text {net }}$-Network produced by the plant, $\mathrm{kW}$;

$\dot{E}_{\text {gf_in }}$ - Total exergy of geofluid input to the power plant, kW;

$\dot{W}_{\text {turbine }}$-Total work produced by turbines, $\mathrm{kW}$;

$\eta_{\mathrm{g}}$-Electric generator efficiency;

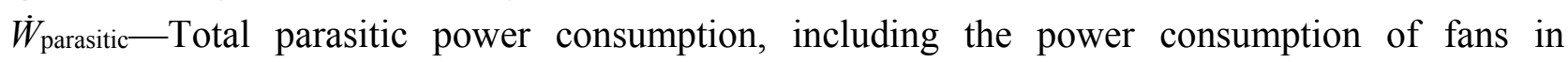
air-cooled condensers ( $\left.\dot{W}_{\text {fan_cond }}\right)$ and all other geofluid pumps $\left(\sum \dot{W}_{\mathrm{gp}, i}\right)$ power consumptions.

For air-cooled cycles, $\dot{W}_{\text {parasitic }}=\sum \dot{W}_{\mathrm{gp}, i}+\dot{W}_{\text {fan_cond, }} \mathrm{kW}$;

$\dot{m}_{\mathrm{gf}}$ in - geofluid mass flow rate fed to the power plants, $\mathrm{kg} / \mathrm{s}$.

$e_{\mathrm{gf}}$ in - Specific exergy of the geofluid fed to the power plant, $\mathrm{kJ} / \mathrm{kg}$.

In addition to the plant utilization efficiency $\eta_{U}$, the energy efficiency $\left(\eta_{I}\right)$ and exergy efficiency $\left(\eta_{I I}\right)$ of the plants are also calculated [25]:

$$
\begin{aligned}
& \eta_{\mathrm{I}}=\frac{\dot{W}_{\mathrm{net}}}{\Delta \dot{H}_{\mathrm{hf}}}=\frac{\dot{W}_{\text {turbine }} \eta_{\mathrm{g}}-\dot{W}_{\text {parasitic }}}{\dot{m}_{\mathrm{gf} \_ \text {in }} \Delta h_{\mathrm{gf}}} \\
& \eta_{\mathrm{II}}=\frac{\dot{W}_{\mathrm{net}}}{\Delta \dot{E}_{\mathrm{gf}}}=\frac{\dot{W}_{\text {turbine }} \eta_{\mathrm{g}}-\dot{W}_{\text {parasitic }}}{\dot{m}_{\mathrm{gf} \_ \text {in }} \Delta e_{\mathrm{gf}}}
\end{aligned}
$$

where:

$\Delta \dot{H}_{\mathrm{hf}}$ - the total enthalpy difference between the geofluid fed to and leaving the plant, $\mathrm{kW}$;

$\Delta h_{\mathrm{gf}}$ - the specific enthalpy difference between the geofluid fed to and leaving the plant, $\mathrm{kJ} / \mathrm{kg}$;

$\Delta \dot{E}_{\mathrm{gf}}$ - the total exergy difference between the geofluid fed to and leaving the plant, $\mathrm{kW}$;

$\Delta e_{\mathrm{gf}}$ - the specific exergy difference between the geofluid fed to and leaving the plant, $\mathrm{kJ} / \mathrm{kg}$.

We also define a specific net power output as geofluid effectiveness $G F_{e}$ :

$$
G F_{e}=\frac{\dot{W}_{\text {net }}}{\dot{m}_{\mathrm{gf} \_ \text {in }}}=\eta_{\mathrm{U}} e_{\mathrm{gf} \_ \text {in }}
$$

which has units of $\mathrm{kJ} / \mathrm{kg}$ and is a measure of the specific net work of the geofluid. For given feed geofluid temperature and pressure (given $e_{\mathrm{gf}}$ in), $G F_{e}$ is determined by $\eta_{\mathrm{U}} . G F_{\mathrm{e}}$ and $\eta_{\mathrm{U}}$ are thus thermodynamically equivalent. We used $G F_{\mathrm{e}}$ as the thermodynamic criterion to compare power plants, just as many authors did, because it is proportional to the total power output of the plants. Other efficiencies are computed for reference. 


\subsection{Model Design Specifications and Parameters}

To validate our simulation inputs, our modeling is on the same basis with the binary cycle modeling from [13], which also used ASPEN PLUS for their simulation. Furthermore, the results from [13], obtained there in the low geofluid temperature range of $100-200{ }^{\circ} \mathrm{C}$, could thus supplement those from our study that was for temperatures $>200^{\circ} \mathrm{C}$. Inputs and constraints used in model developments are listed in Table 1.

Table 1. Inputs and constraints of thermodynamic analysis.

\begin{tabular}{|c|c|c|}
\hline Parameter & Symbol & Value or Constraint \\
\hline Cooling fluid into condenser, and the Dead State & - & - \\
\hline Temperature & $T_{\text {cf } \_ \text {in }}, T_{0}$ & $20^{\circ} \mathrm{C}$ \\
\hline Pressure & $P_{\text {cf } \_ \text {in }}, P_{0}$ & $0.1 \mathrm{MPa}$ \\
\hline Absolute humidity of air & $d_{\text {in }}$ & $\begin{array}{c}6.33 \mathrm{~g} \text { water vapor per } \mathrm{kg} \text { of } \\
\text { dry air }\end{array}$ \\
\hline Condenser & - & - \\
\hline Pinch point temperature difference & $\Delta T_{\mathrm{pp}}$ & $10^{\circ} \mathrm{C}$ \\
\hline Pressure drop & $\Delta P_{\text {cond }}$ & 0 \\
\hline Condensing temperature & $T_{\text {cond }}$ & $50{ }^{\circ} \mathrm{C}$ \\
\hline Condensing pressure & $P_{\text {cond }}$ & $0.0123 \mathrm{MPa}$ \\
\hline Efficiencies & - & - \\
\hline Turbine isentropic efficiency & $\eta_{I I, t b}$ & 0.85 \\
\hline Pump isentropic efficiency & $\eta_{\mathrm{II}, \text { pump }}$ & 0.80 \\
\hline Generator energy efficiency & $\eta_{\mathrm{g}}$ & 0.98 \\
\hline Others & - & - \\
\hline Flashing pressure & $P_{\mathrm{FL}}$ & $\geq 0.1 \mathrm{MPa}$ \\
\hline Geofluid injection temperature & $T_{\text {gf_out }}$ & $\geq 60^{\circ} \mathrm{C}$ \\
\hline Geofluid injection pressure & $P_{\text {gf_out }}$ & $P_{\text {gf } \_ \text {in }}$ \\
\hline Specific parasite power consumption of cooling system & $\dot{W}_{\text {fan }} / \dot{m}_{\text {air }}$ & $0.25 \mathrm{~kJ} /(\mathrm{kg}$ air $)[13]$ \\
\hline Mass flow rate of geofluid into the cycle & $\dot{m}_{\mathrm{gf} \text { in }}$ & $100 \mathrm{~kg} / \mathrm{s}$ \\
\hline Subcritical feed geofluid pressure & $P_{\mathrm{gf} \_ \text {in }}$ & $P_{\text {gf_in }}=P_{\text {sat }}\left(T_{\text {gf-in }}\right)$ \\
\hline Pressure difference of two mixing streams & $\Delta P_{\text {mix }}$ & 0 \\
\hline
\end{tabular}

In EGS application, mineral precipitation in injection wells should be avoided to reduce clogging of the geofluid flow paths in the hot rocks and thus preserve the heating of the geofluid. The geofluid re-injection temperature should therefore have a low bound limit to prevent mineral precipitation in the injection wells and the underground reservoir. This temperature is dependent on the type and concentration of minerals, which is site dependent, and past studies showed that this temperature to be around $60-80{ }^{\circ} \mathrm{C}[1,8,10]$. We choose $60{ }^{\circ} \mathrm{C}$ in this study.

For air-cooled cycles, the parasitic power $\dot{W}_{\text {fan_cond }}$ is estimated as the fan electricity consumption recommended in [13] of $0.25 \mathrm{~kJ} /\left(\mathrm{kg}\right.$ air). The power consumption of geofluid pumps $\sum \dot{W}_{\mathrm{gp}, i}$ is calculated by the simulation programs, depending on the pressure increase requirement of the pumps. 
Other assumptions are:

1. The flashing process is isenthalpic [2].

2. Only streams of the same pressure are allowed to mix, and mixing process is isobaric [2]. Streams are brought to the same pressure either by pumps or valves before mixing.

3. The fluid properties are calculated in ASPEN PLUS [24] using the International Association for Properties of Steam (Steam_IAPWS).

\subsection{Power Plant Configurations}

Having considered the plant configuration options most suitable for EGS geofluid feed temperature ( $T_{\mathrm{gf} \text { _in }}$ ) ranges from 200 to $800{ }^{\circ} \mathrm{C}$, the power plants studied in this work are single-flash plant (SF), double-flash plant (DF), triple-expansion plant (TENS), double-expansion plant (DE) and single-expansion plant (SE). To increase the vapor fraction at turbine outlets to $90 \%$, a triple-expansion cycle with superheating (TES) was also studied. The basic flow sheets of the cycles and sample temperature-entropy $(T-S)$ diagrams of the above six cycles are shown in Figure 1.

Figure 1. Conceptual flow sheets and $T-S$ diagrams of (a) single-flash plant when $T_{\text {gf_in }}=200{ }^{\circ} \mathrm{C}$; (b) double-flash plant, when $T_{\text {gf_in }}=300{ }^{\circ} \mathrm{C}$; (c) triple-expansion plant when $T_{\text {gf_in }}=400{ }^{\circ} \mathrm{C}$ and $P_{\text {gf_in }}=23 \mathrm{MPa}$; (d) triple-expansion plant with superheating when $T_{\mathrm{gf}_{-} \text {in }}=400{ }^{\circ} \mathrm{C}$ and $P_{\mathrm{gf}}$ in $=23 \mathrm{MPa}$; (e) double-expansion plant when $T_{\mathrm{gf}_{-} \text {in }}=500{ }^{\circ} \mathrm{C}$ and $P_{\text {gf_in }}=23 \mathrm{MPa}$; and (f) single-expansion plant when $T_{\mathrm{gf} \_}$in $=650^{\circ} \mathrm{C}$ and $P_{\text {gf in }}=23 \mathrm{MPa}$. COND: condenser; CS: cyclone separator; FL: flasher; HPT: high pressure turbine; HPT-SH: super heater before HPT; LPT: low pressure turbine; LPT-SH: super heater before LPT; PUMP1: geofluid pump; PUMP2: geofluid re-injection pump; SPT: super pressure turbine; numbers and "GF_IN", "GF_OUT": geofluid streams (liquid phase geofluid "-"; vapor phase "_-"; liquid-vapor mixture "-._"”; supercritical geofluid "=”); "CF_IN" and "CF_OUT": cooling fluid stream "..".

(a) $\mathrm{SF}$

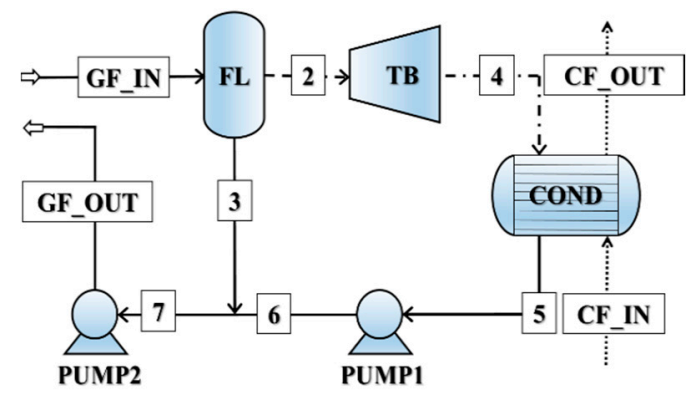

(b) DF

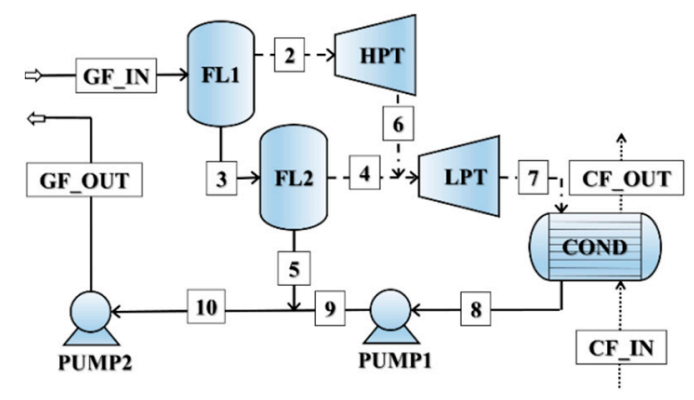

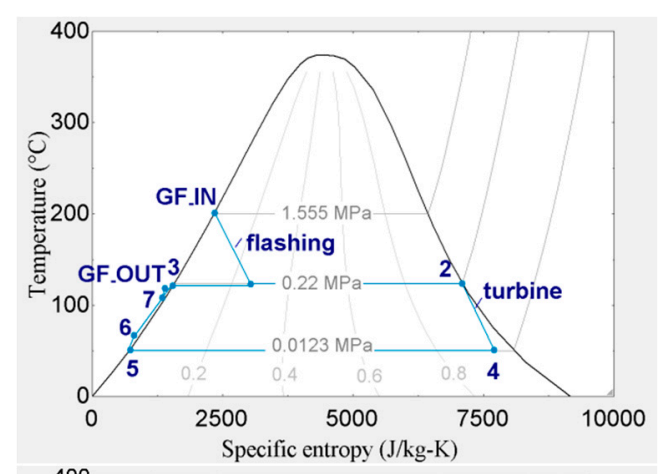

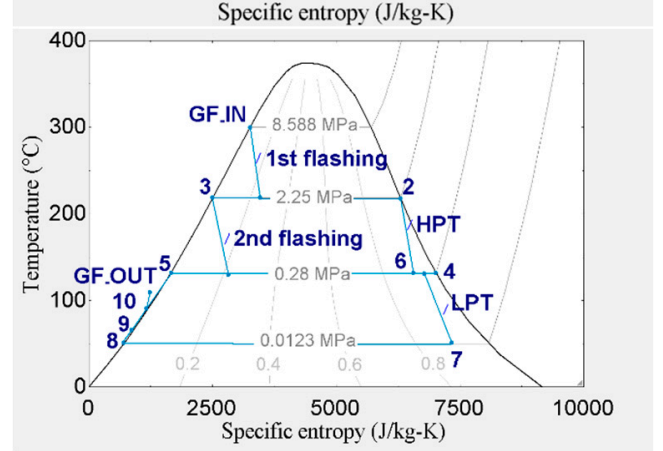


Figure 1. Cont.

(c) TENS

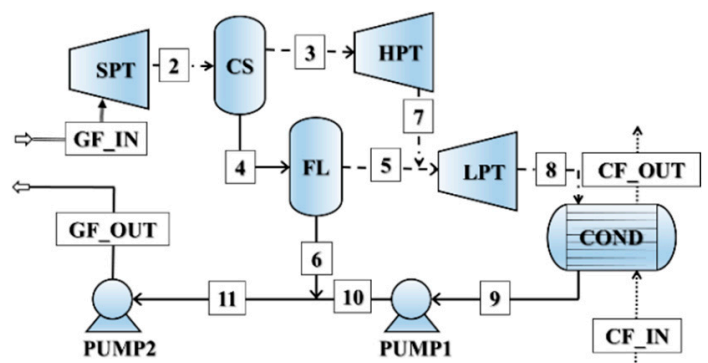

(d) TES

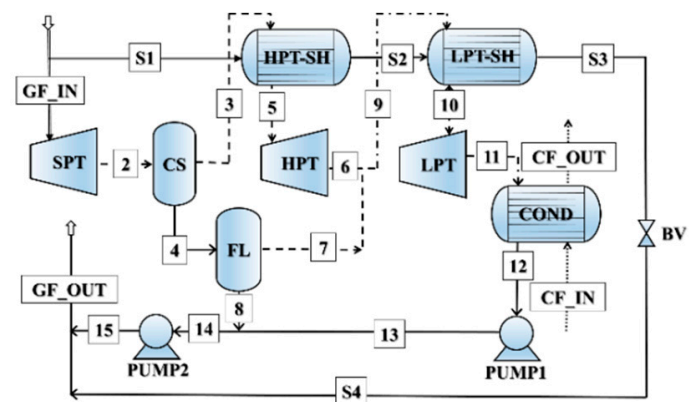

(e) $\mathrm{DE}$

(f) $\mathrm{SE}$
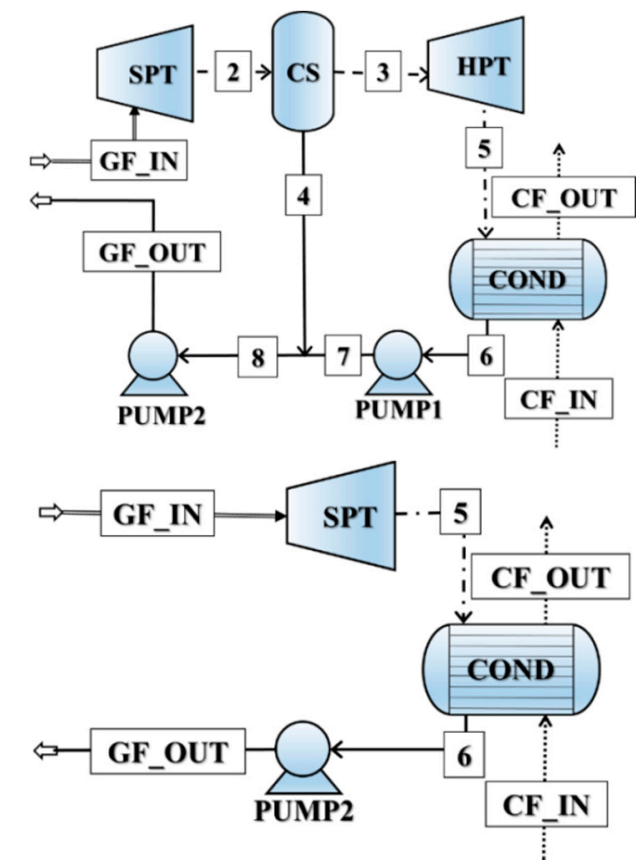
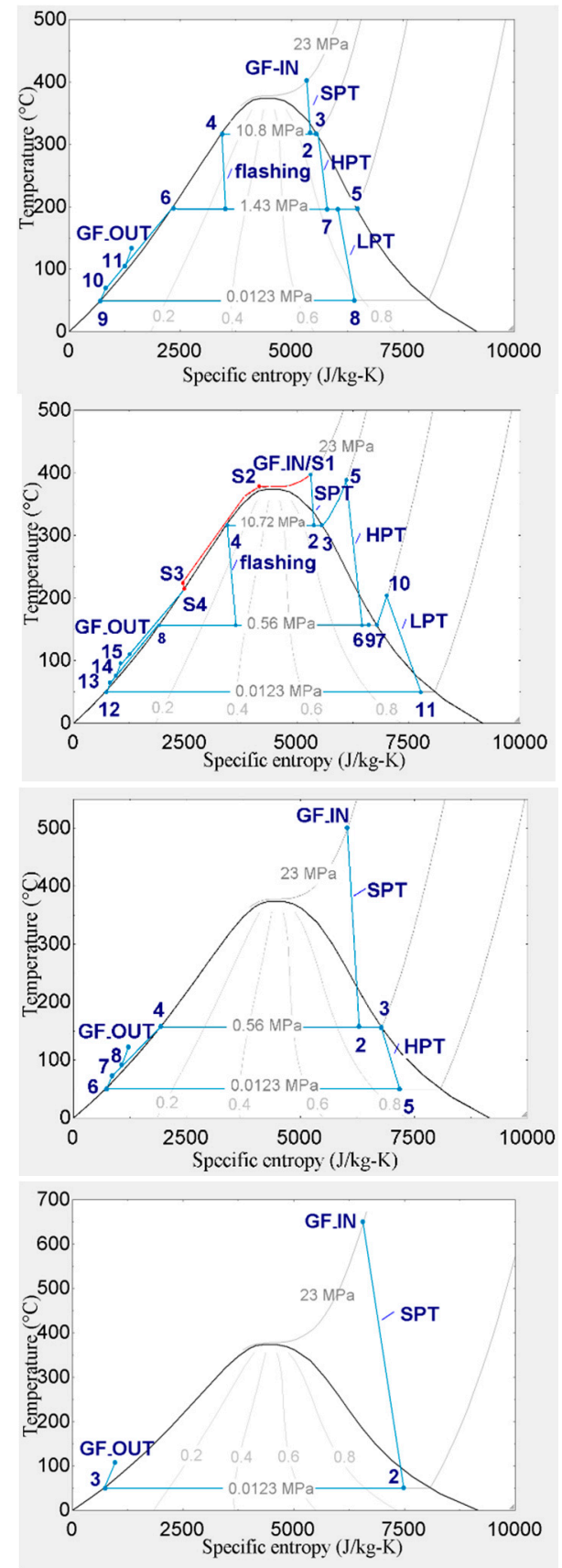

A single-flash plant (Figure 1a) flashes liquid phase geofluid at a pressure lower than the geofluid feed pressure (in FL), to generate a vapor and liquid mixture. The vapor is then separated from the mixture to serve as the feed to the steam turbine to generate work. Exhausted steam from turbine (TB) is condensed in the condenser (COND) to saturated liquid. PUMP1 is used to increase the pressure of saturated liquid 5 to super-cooled liquid 6, which has the same pressure as saturated liquid 3 before re-injected into the geothermal reservoir. It is assumed that no geofluid is lost in this cycle. The single-flash plant is the most conventional of all power plant designs and is widely used for geofluid temperatures over $150^{\circ} \mathrm{C}[2]$.

A double-flash plant (Figure 1b) is similar to a single-flash plant except that the saturated liquid from FL1 is flashed one more time in a secondary flasher (FL2) to generate more vapor [2] and can 
thus generate more electricity. Such plants are naturally more complex and expensive, and require some more maintenance.

A triple-expansion plant (Figure 1c) uses supercritical geofluid [1]. It is a variant of the double-flash plant, with the additional topping super-pressure turbine (SPT) where the SPT is designed to handle pressures exceeding the critical pressure of water $(22.06 \mathrm{MPa})$ [1]. The supercritical geofluid expands in the SPT to a vapor-liquid mixture phase, state 2. Then the mixture is separated isobarically in the CS to vapor 3 and liquid 4. Vapor 3 is then fed to the HPT, and the liquid 4 from CS is flashed again in FL, same as double-flash plant. The mixture of exhaust 7 from the HPT and the vapor 5 from the FL are then fed to the LPT. The condensed geofluid 9 is pressurized to the same pressure as liquid 6 from the FL, and then re-injected to the underground reservoir. Power is generated in all three turbines.

Figure 1c shows that the vapor fractions at the HPT and LPT outlets $\left(\mathrm{VF}_{7}\right.$ and $\left.\mathrm{VF}_{8}\right)$ are lower than 0.90 for $T_{\text {gf }_{-} \text {in }}=400{ }^{\circ} \mathrm{C}$, which should be avoided to protect turbine blades from liquid erosion. This problem can be solved by superheating the SPT outlet stream and the HPT outlet stream (Figure 1d). The heat source to superheat the streams is still the geofluid from the underground reservoir, and its mass flow rate is included in the analysis. The vapor 3 from the CS is superheated to state 5 before feeding to the HPT. The exhaust 6 from the HPT mixes with the vapor 7 from the FL, and then the mixture is superheated to state 10 before fed to the LPT. The condensed geofluid 12 mixes with liquid 8 from the FL and then further mixes with exhausted superheating geofluid $\mathrm{S}_{4}$ before re-injection to the underground reservoir.

Increasing the geofluid inlet temperature to the power plant may reach a temperature at which the SPT could expand the geofluid to a state where CS temperature is lower than $150{ }^{\circ} \mathrm{C}$. Flashing below $150{ }^{\circ} \mathrm{C}$ is usually unnecessary [2]. Then the FL is eliminated and the triple-expansion plant is reduced to a double-expansion plant (Figure 1e) where the LPT is eliminated too. The vapor 3 from the CS is fed to HPT. The exhaust 5 from HPT is then condensed to stream 6, and then compressed to mix with the liquid 4 from the CS. The mixture is pressurized to injection pressure before re-injecting to the reservoir. Different from the triple-expansion plant, there is no flashing of the geofluid.

Further increase of the geofluid inlet temperature will lower the CS temperature to near the condensing temperature, then the CS and HPT could also be eliminated and the double-expansion plant becomes a single-expansion one (Figure 1f). The geofluid is expanded in SPT, condensed and re-injected to the geothermal reservoir.

\subsection{Embodied Energy of Surface Plants}

In this study, we focus on selection of power plant types, so only the embodied energy of surface power plants is calculated and compared. Therefore, other important energy consumptions in an EGS project such as drilling the injection/production wells and reservoir fracturing are beyond the scope of this paper. The embodied energy of power plants, i.e., the energy consumed for building the plants and maintaining their operation, is an important factor in determining their energy return on investment (EROI). This is especially important when the energy sources are of low density, such as with any renewable sources and waste heat, and thus require much equipment or area, or when the energy conversion plants are made more complex to increase their efficiency relative to the direct energy input. 
In pursuit of higher efficiency we considered increasingly complex geothermal power plants and it was of interest to examine, at least approximately, how it affects their specific embodied energy (similar to EROI).

The embodied energy of power plants considered in this work is simplified to the embodied energy of the installed equipment, where the embodied energy of labor, components assembly, site preparation, plant maintenance and such details are not considered for simplicity. Since embodied energy was not considered in past studies of geothermal systems at all, this analysis still serves as a modest contribution to knowledge. The installation equipment weights $M_{\mathrm{EQ}}$ (in $\mathrm{kg}$ stainless steel, including all the connection pipes) used in the analyzed power plants are extracted from ASPEN PLUS "US-IP" economic analysis [23], which is a built-in module to estimate the equipment weight for flow sheets. For example, the weight of a heat exchanger is a function of its heat load, pressure, type of exchangers and such. The embodied energy of surface plants is thus simplified as:

$$
E B_{\mathrm{PP}}=e b_{\mathrm{EQ}} M_{\mathrm{EQ}}
$$

where the specific embodied energy of all the equipment is taken to be $e b_{\mathrm{EQ}}=56.7 \mathrm{MJ} / \mathrm{kg}$ (we assume for simplicity that all the equipment is made of stainless steel) [26]. The specific embodied energy of the whole power plants is defined to be:

$$
e b_{\mathrm{PP}}=\frac{E B_{\mathrm{PP}}}{\dot{W}_{\text {net }}}
$$

where the denominator is the net power output capacity of power plants.

\section{Results and Discussion}

\subsection{Approach to Optimization}

Optimization of the single-flash and double-flash plants (described in Section 2.3) is approached by varying the flashing pressures to achieve maximal geofluid effectiveness $G F_{e}$. Geofluid inflow temperatures in the range $200-350{ }^{\circ} \mathrm{C}$ are assumed. There is an optimal flash pressure because increasing the flash pressures results in higher specific enthalpy vapor but at the same time lower vapor mass flow rate, and vice versa. Since the geofluid effectiveness $G F_{e}$ is proportional to vapor specific enthalpy times vapor mass flow rate, there is a tradeoff between vapor specific enthalpy and vapor mass flow rate. In the analysis, the vapor fraction leaving the turbines is set to be greater than 0.80 for flash type plants, to protect the turbines.

When the geofluid from underground reservoir is supercritical, an SPT is used, and the supercritical geofluid expands to a liquid and vapor mixture phase. The optimum of triple expansion plants is sought by varying the CS and FL pressures, under the constraint of SPT outlet vapor fraction kept in the range $0.90-1$ and $T_{\text {gf_out }} \geq 60^{\circ} \mathrm{C}$. As implied above, higher CS pressure results in higher geofluid flow rate feed to the flasher, resulting in more work produced by HPT and LPT, but less work produced by SPT. Keeping $T_{\text {gf } \_ \text {in }}=400{ }^{\circ} \mathrm{C}$, the performances for $P_{\text {gf } \_ \text {in }}=23 \mathrm{MPa}, 25 \mathrm{MPa}$ and $27 \mathrm{MPa}$ are shown in Table 2. For supercritical geofluid, lowering the geofluid inflow pressure $P_{\text {gf }}$ in causes both $G F_{e}$ and $e b$ PP to improve, in the studied range $G F_{e}$ becomes $17 \%$ higher and $e b$ PP $11 \%$ lower. We thus conclude that $P_{\text {gf }}$ in should be kept as low as possible to maintain the supercritical condition of the geofluid. The lowest $P_{\mathrm{gf}}$ in to use could equal the critical pressure of the geofluid (22.06 MPa for 
water). Practically, however, fluids working near their critical points should be avoided if possible, because there they undergo sharp thermodynamic and transport properties transitions [1], so in this work, we consider $P_{\text {gf in }}=23 \mathrm{MPa}$ for the supercritical geofluid to calculate maximum power production from geofluid of given temperature. This pressure is determined by the underground pressure field of the EGS system (in wells and engineered reservoir), and the power plants can utilize geofluid at any pressure. The triple-expansion plant simulations are performed for $T_{\mathrm{gf}}$ in values of $400{ }^{\circ} \mathrm{C}$, $450{ }^{\circ} \mathrm{C}$ and $500{ }^{\circ} \mathrm{C}$ and all at $P_{\text {gf }}$ in $=23 \mathrm{MPa}$.

Table 2. Optimal efficiencies of the air-cooled triple-expansion plant as a function of $P_{\text {gf_in }}$ at $T_{\text {gf } \_ \text {in }}=400{ }^{\circ} \mathrm{C}$.

\begin{tabular}{cccc}
\hline $\boldsymbol{P}_{\mathbf{g}_{\text {in }},}, \mathbf{M P a}$ & $\mathbf{2 3}$ & $\mathbf{2 5}$ & $\mathbf{2 7}$ \\
\hline$G F_{e}, \mathrm{~kJ} / \mathrm{kg}$ & 781.36 & 733.04 & 666.66 \\
$e b_{\mathrm{PP}}, \mathrm{TJ} / \mathrm{MWe}$ & 4.66 & 4.90 & 5.25 \\
\hline
\end{tabular}

The vapor fractions $(V F)$ at turbine outlets are very low ( $<80 \%$ from the $T-S$ graph in Figure 1c) which is undesirable because liquid droplets could erode the turbine [1,2]. Typically, the design of power plants requires the $V F$ at turbine outlets to be greater than $90 \%$ [2]. One way to increase the $V F$ is by superheating the turbine inlet streams, as shown in Figure $1 \mathrm{~d}$. For $T_{\mathrm{gf}-\mathrm{in}}=400{ }^{\circ} \mathrm{C}$ and $P_{\mathrm{gf}}$ in $=23 \mathrm{MPa}$, the degree of superheat of HPT-SH, LPT-SH and the mass flow rate ratio $\dot{m}_{\mathrm{s} 1} / \dot{m}_{\mathrm{gf}}$ in (ratio of mass flow rate of superheating stream to mass flow rate of geofluid fed to cycle to generate electricity) are sought and chosen to achieve maximal geofluid effectiveness $G F_{e}$ for $V F$ greater than $90 \%$ at the SPT, HPT and LPT outlets. The maximal geofluid effectiveness was obtained when the superheating degree of HPT-SH and LPT-SH are $70{ }^{\circ} \mathrm{C}$ and $50{ }^{\circ} \mathrm{C}$, respectively, and the mass flow rate ratio $\dot{m}_{s} / \dot{m}_{g f_{-} i n}=0.3$. The simulation results of triple-expansion plant with superheating (TES) compared to triple-expansion plant without superheating (TENS) are shown in Table 3. In the superheating case, for $100 \mathrm{~kg} / \mathrm{s}$ geofluid fed to the power plant $77 \mathrm{~kg} / \mathrm{s}$ is used to generate electricity while $23 \mathrm{~kg} / \mathrm{s}$ is used as superheating heat source, therefore the $G F_{e}$ is $28.3 \%$ lower than the non-superheating one. The TES also has $145.9 \%$ higher $e b_{\mathrm{PP}}$ than non-superheating ones, indicating the extent of the net power output and embodied energy input sacrifice needed to increase the vapor fraction at turbine outlets. An alternative to such superheating is of course to use droplet separators at the turbine inlet, which would however, raise cost and also create a pressure drop that reduces efficiency, or to use more erosion resistant materials in the turbine.

For geofluid temperatures $T_{\mathrm{gf}}$ in $>500{ }^{\circ} \mathrm{C}$, there is no solution of CS and FL pressures for TES plant that could satisfy all the constraints of $0.90 \leq V F_{2}<1.0, P_{\mathrm{FL}}>0.1 \mathrm{MPa}$ (flash above surrounding pressure) and $T_{\mathrm{gf}_{-} \text {out }} \geq 60{ }^{\circ} \mathrm{C}$. Therefore, a double-expansion plant will be used instead of the triple-expansion one.

For geofluid temperatures $T_{\mathrm{gf}}$ in of $500-700{ }^{\circ} \mathrm{C}$, the $\mathrm{CS}$ pressure is optimized to achieve maximum geofluid effectiveness $\left(G F_{e}\right)$. However, for $T_{\mathrm{gf}}$ in $\geq 550{ }^{\circ} \mathrm{C}$, there is no CS pressure that can satisfy both $V F_{2} \leq 1.0$ and $T_{\text {gfout }} \geq 60^{\circ} \mathrm{C}$. Increasing the condensing temperature to $60^{\circ} \mathrm{C}$ will satisfy $T_{\text {gfout }} \geq 60{ }^{\circ} \mathrm{C}$. Higher condensing temperatures will, however, reduce the geofluid effectiveness. Comparisons of double-expansion plant with a condensing temperature of $50{ }^{\circ} \mathrm{C}$ and $60{ }^{\circ} \mathrm{C}$ when $T_{\text {gf_in }}=700{ }^{\circ} \mathrm{C}$ and $P_{\text {gf } \_ \text {in }}=23 \mathrm{MPa}$ are listed in Table $4 . G F_{e}$ decreases by $3.5 \%(46 \mathrm{~kJ} / \mathrm{kg}$, corresponding to net power 
output decrease of $0.46 \mathrm{MW} /{ }^{\circ} \mathrm{C}$ ) as the condensing temperature is increased from 50 to $60{ }^{\circ} \mathrm{C}$. $e b$ PP is slightly lower when condensing at $60{ }^{\circ} \mathrm{C}$.

Table 3. Comparison of the air-cooled triple-expansion plants without (TENS) and with (TES) superheating for $T_{\mathrm{gf}}$ in $=400{ }^{\circ} \mathrm{C}$ and $P_{\mathrm{gf}}$ in $=23 \mathrm{MPa}$.

\begin{tabular}{ccc}
\hline Cases & TENS & TES \\
\hline$\dot{m}_{\mathrm{sI}_{1} / \dot{m}_{\mathrm{gf} \_ \text {in }}}$ & 0 & 0.3 \\
$\Delta T_{\mathrm{SPT} \text { SHH }}^{\mathrm{SH}},{ }^{\circ} \mathrm{C}$ & 0 & 70 \\
$\Delta T_{\mathrm{SPT}-\mathrm{LH}}^{\mathrm{SH}},{ }^{\circ} \mathrm{C}$ & 0 & 50 \\
$V F$ after SPT & 0.90 & 0.90 \\
$V F$ after HPT & 0.81 & 0.90 \\
$V F$ after LPT & 0.72 & 0.90 \\
$G F_{e}, \mathrm{~kJ} / \mathrm{kg}$ & 781.36 & 560.45 \\
$e b_{\mathrm{PP}}, \mathrm{TJ} / \mathrm{MWe}$ & 4.66 & 11.46 \\
\hline
\end{tabular}

Table 4. The effect of the condensing temperature $T_{\text {cond }}$ of the air-cooled double-expansion plant for $T_{\text {gf_in }}=700{ }^{\circ} \mathrm{C}$ and $P_{\text {gf } \_ \text {in }}=23 \mathrm{MPa}$.

\begin{tabular}{ccc}
\hline $\boldsymbol{T}_{\text {cond, }}{ }^{\circ} \mathbf{C}$ & $\mathbf{5 0}$ & $\mathbf{6 0}$ \\
\hline$G F_{e}, \mathrm{~kJ} / \mathrm{kg}$ & 1330.59 & 1284.74 \\
$T_{\text {gf out }},{ }^{\circ} \mathrm{C}$ & 50.61 & 60.66 \\
$e b_{\text {PP }}, \mathrm{TJ} / \mathrm{MWe}$ & 3.69 & 3.55 \\
\hline
\end{tabular}

For geofluid temperatures $T_{\mathrm{gf}_{-} \text {in }} \geq 650{ }^{\circ} \mathrm{C}$, the vapor fraction at the SPT outlet of the double-expansion plant is as high as 0.99 for the optimal thermodynamic performance case, and thus a simpler, single-expansion plant could be used. The geofluid outlet temperature will roughly equal the condensing temperature for this plant. For comparison with other plants, the condensing temperature is still set to $50^{\circ} \mathrm{C}$.

An important conclusion is that superheating the turbines' inlet streams could increase the vapor fraction at turbine outlets, and raising the condensation temperature could increase the geofluid re-injection temperature $T_{\text {gf_out, }}$ but both methods reduce the plants' net power output by $28 \%$ and $3.9 \%$.

\subsection{Results Validation}

To validate our ASPEN PLUS simulation method, we compared our results of three types of power plants with the results from Chapter 7 of [1]. We adopted all the assumptions of [1] in our simulation to generate results when the ASPEN PLUS model is converged (mass and heat balance are satisfied with absolute residual of $10^{-6}$ ). The comparisons are shown in Table 5. The assumption in [1] is based on "Baumann rule", that $1 \%$ moisture in the turbine outlet downgrades the isentropic efficiency of turbine by $1 \%$ [27]. In our calculation, we used an average turbine isentropic efficiency, which causes the $<1.5 \%$ difference of our results with the ones from [1]. Since the relative error is smaller than $1.5 \%$, our simulation models are considered to produce very acceptable results. 
Table 5. Power plant simulation results validation of this work.

\begin{tabular}{ccccc}
\hline \multirow{2}{*}{$\boldsymbol{T}_{\text {gf } \_ \text {in }}{ }^{\circ} \mathbf{C}$} & Plant Type & $\begin{array}{c}\boldsymbol{G} F_{\boldsymbol{e}} \text { Calculated in [1] } \\
\mathbf{k J} / \mathbf{k g}\end{array}$ & $\begin{array}{c}\boldsymbol{G} \boldsymbol{F}_{\boldsymbol{e}} \text { Calculated in This Work } \\
\mathbf{k J} / \mathbf{k g}\end{array}$ & $\begin{array}{c}\text { Relative } \\
\text { Difference }\end{array}$ \\
\hline 200 & $\mathrm{SF}$ & 53.9 & 54.48 & $1.08 \%$ \\
250 & $\mathrm{DF}$ & 123.5 & 125.24 & $1.41 \%$ \\
$400\left(P_{\mathrm{gf} \text { in }}=25 \mathrm{MPa}\right)$ & $\mathrm{TE}$ & 727.3 & 733.04 & $0.79 \%$ \\
\hline
\end{tabular}

\subsection{Results for Air-Cooled Cycles}

The simulation results for all five power plant configurations (excluding TES, for which there is one performance point given in Table 3) with air-cooled condensers, showing the sensitivity of the thermodynamic performance parameters to the geofluid inlet temperature $T_{\mathrm{gf}}$ in are shown in Figure 2 .

It can be seen that the geofluid effectiveness $G F_{e}$ :

$\circ$ Generally increases with $T_{\mathrm{gf}}$ in.

- Is significantly higher for supercritical geofluid $\left(G F_{e}>750 \mathrm{~kJ} / \mathrm{kg}\right)$ than for subcritical geofluid $\left(G F_{e}<300 \mathrm{~kJ} / \mathrm{kg}\right)$, showing an upward jumps in the range of $350{ }^{\circ} \mathrm{C}<T_{\mathrm{gf} \text { in }}<400{ }^{\circ} \mathrm{C}$. When the geofluid reaches supercritical condition, it can expand in a turbine (SPT) to generate work, thus significantly raises the cycle's net power output.

- For subcritical geofluid, double-flash plants have $24.3 \%-29.0 \%$ higher geofluid effectiveness $G F_{e}$ than single flash plant.

○ When $T_{\mathrm{gf} \_}$in $=500{ }^{\circ} \mathrm{C}$, the triple-expansion plant and double-expansion plant have same $G F_{e}$.

○ When $T_{\mathrm{gf} \text { in }}=650-700{ }^{\circ} \mathrm{C}$, the double-expansion plant has a $G F_{e}$ around $2 \%$ higher than the single-expansion plant.

Table 6. Itemized equipment weights of selected power plants.

\begin{tabular}{ccccccccc}
\hline Plant Type & \multicolumn{2}{c}{ SF } & \multicolumn{2}{c}{ DF } & TENS & TES & DE & SF \\
\hline$T_{\text {gf-in, }}{ }^{\circ} \mathrm{C}$ & 250 & 250 & 250 & 250 & 400 & 400 & 700 & 700 \\
Cooling medium & air & water & air & water & air & air & air & air \\
Total equipment weights, ton & 1838.96 & 657.33 & 2371.97 & 492.80 & 2293.33 & 4041.38 & 3092.27 & 3187.33 \\
COND & $93.4 \%$ & $18.7 \%$ & $92.6 \%$ & $18.1 \%$ & $90.8 \%$ & $82.7 \%$ & $85.2 \%$ & $87.1 \%$ \\
CS & - & - & - & - & $0.7 \%$ & $0.4 \%$ & $0.5 \%$ & - \\
CTOWER & - & $60.5 \%$ & - & $58.6 \%$ & - & - & - & - \\
FL1 & $2.8 \%$ & $8.0 \%$ & $2.1 \%$ & $6.7 \%$ & $0.4 \%$ & $0.2 \%$ & - & - \\
FL2 & - & - & $1.3 \%$ & $2.9 \%$ & - & - & - & - \\
HPT & $2.8 \%$ & $10.3 \%$ & $1.3 \%$ & $4.4 \%$ & $2.4 \%$ & $5.2 \%$ & $2.7 \%$ & - \\
HPT-SH & - & - & - & - & - & $3.1 \%$ & - & - \\
LPT & - & - & $2.0 \%$ & $7.2 \%$ & $4.3 \%$ & $5.6 \%$ & - & - \\
LPT-SH & - & - & - & - & - & $1.4 \%$ & - & - \\
PUMP1 & $0.3 \%$ & $0.4 \%$ & $0.2 \%$ & $0.5 \%$ & $0.2 \%$ & $0.1 \%$ & $0.1 \%$ & $0.2 \%$ \\
PUMP2 & $0.8 \%$ & $2.0 \%$ & $0.6 \%$ & $1.6 \%$ & $0.1 \%$ & $0.1 \%$ & $0.2 \%$ & - \\
SPT & - & - & - & - & $1.1 \%$ & $1.2 \%$ & $11.3 \%$ & $12.7 \%$ \\
\hline
\end{tabular}


Figure 2. Geofluid effectiveness (a) and power plant utilization efficiency (b), plant energy efficiency (c) and exergy efficiency (d), power plant embodied energy (e) and power plant specific embodied energy (f) with respect to $T_{\mathrm{gf} \_ \text {in }}$ for different plant configurations with air-cooled condensers. SF: single flash; DF: double flash; TENS: triple expansion without superheating; DE: double expansion; SE: single expansion. The result for TES is in Table 3.

(a)

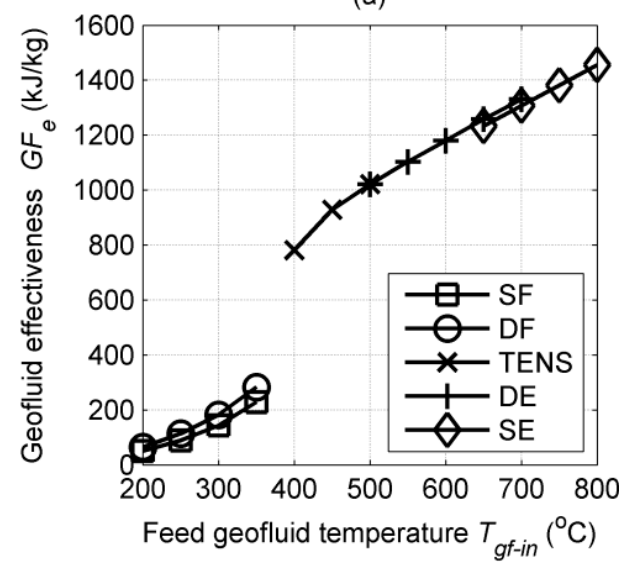

(c)

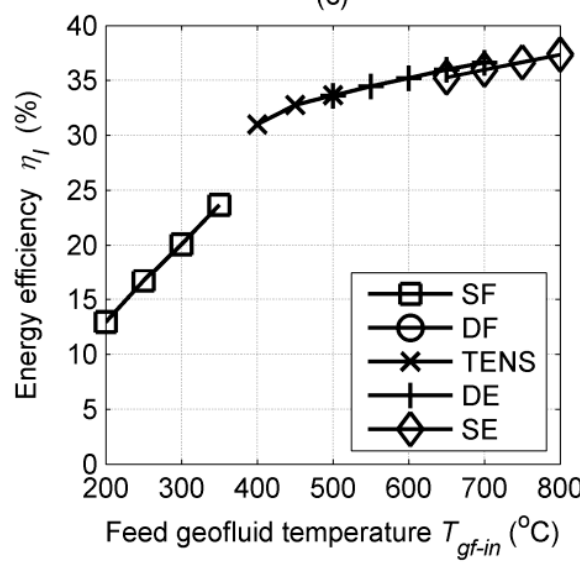

(e)

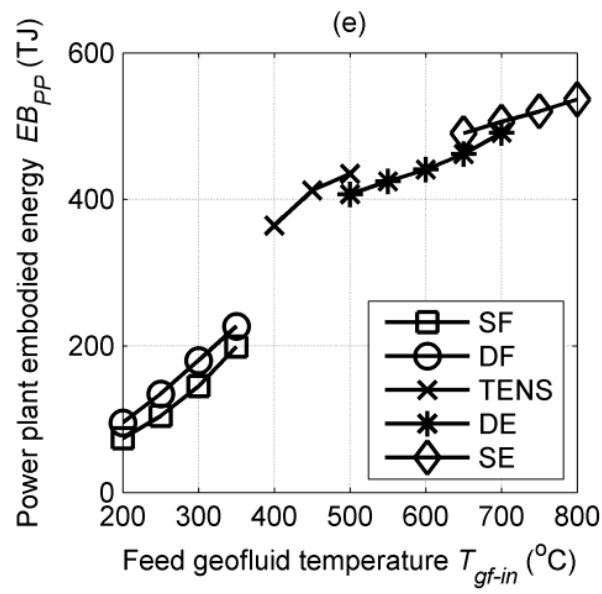

(b)

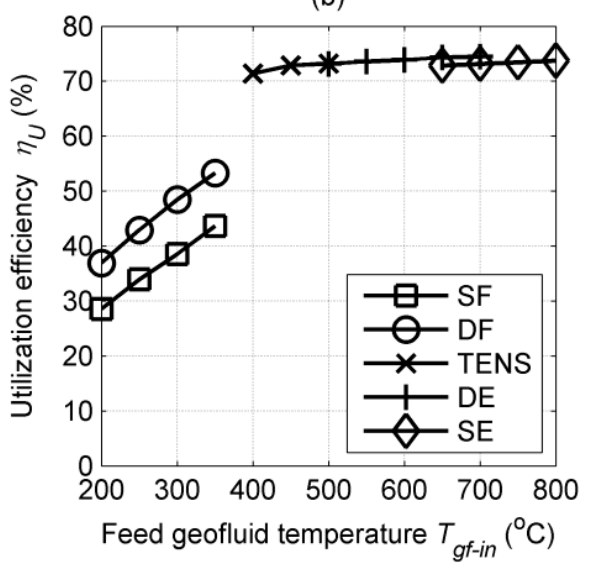

(d)

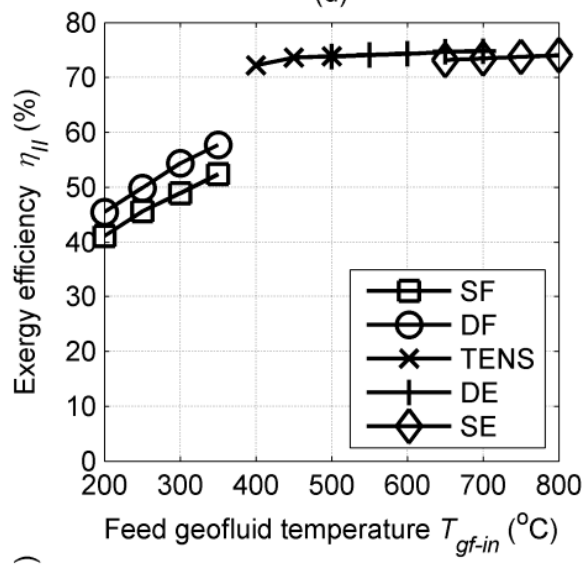

(f)

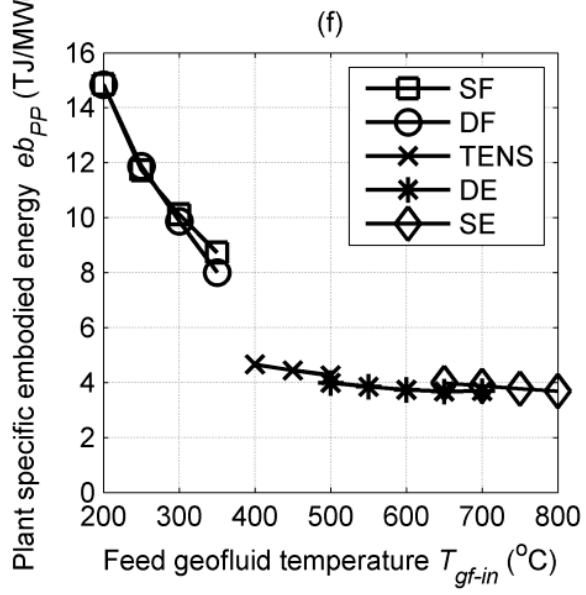

Figure $2 b-d$ show the utilization, energy and exergy efficiency of plants also increase monotonically with geofluid feed temperature $T_{\text {gf in. }}$. Figure $2 \mathrm{e}$ shows that the total embodied energy of surface power plants increases with $T_{\mathrm{gf}}$ in, because the power output and condenser heat load increase too, and they are especially high for supercritical power plants. Table 6 shows the itemized equipment 
weights of selected power plants. The weight of the air-cooled condensers accounts for over $80 \%$ of the total weight of the power plants and thus dominates the embodied energy amount.

To take into account the influence of power plant capacity on its embodied energy, Figure $2 \mathrm{f}$ shows the specific embodied energy of power plants (in TJ/MWe). Supercritical power plants are seen to have a smaller specific embodied energy than subcritical plants because their larger power outputs compensate for the overall larger embodied energy.

\subsection{Comparison of Water-Cooled and Air-Cooled Cycles}

Water-cooled cycles yield higher net power output [2] because they offer lower condensation temperature than air-cooled ones [28]. Water-cooled condensers are modeled with ASPEN PLUS built-in block "Heat Exchanger". Cooling towers are modeled as a two stage absorber with ASPEN PLUS block "Radfrac". Study [29] found that a two stage absorber works similar to a cooling tower and the Murphree efficiency for each stage is found to be 0.927 and 0.763 on average.

For water-cooled cycles, the parasitic power consumption is calculated as $\dot{W}_{\text {parasitic }}=\sum \dot{W}_{\mathrm{gp}, i}+\dot{W}_{\mathrm{cwp}}+$ $\dot{W}_{\text {fan_ctower, }} \mathrm{kW}$, where $\dot{W}_{\text {fan_ctower }}$ is the water-cooled cooling towers power consumption and $\dot{W}_{\text {cwp }}$ is the cooling water pumps power consumption. Since the cooling water pump power consumption $\dot{W}_{\text {cwp }}$ is

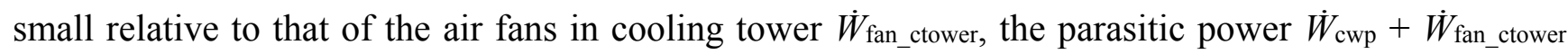
could be roughly estimated to be just the fan electricity consumption recommended in [13] and listed in Table 1. There is water loss in the evaporative cooling tower in a water-cooled cycle, where a fraction of externally supplied cooling water is lost by evaporation in the cooling tower.

To compare operation with an air-cooled condenser to that with a water-cooled condenser, Table 7 lists the geofluid effectiveness $G F_{e}$ and power plant specific embodied energy $e b$ pP of these two cooling methods. As expected, the geofluid effectiveness $G F_{e}$ is lower for the air-cooled system for fixed condensing temperature, because air-cooled fans consume more energy than cooling tower ones due to much larger air flow rate in the air-cooled condenser. In practice, when the ambient air temperature rises above the design air temperature $\left(15^{\circ} \mathrm{C}\right.$ in this work), the designed air flow rate cannot take all the discharged heat from condenser, thus causing the condensation temperature to rise. $G F_{e}$ will thus decrease with increased ambient air temperature. The power plant specific embodied energy $e b$ PP is much larger for air-cooled systems because air-cooled condensers are much larger than water cooled ones due to lower heat transfer coefficients in the former. The air-cooled and water-cooled condenser weights are also listed in Table 6 , showing that water-cooled condensers have a much smaller weight than air-cooled condensers.

Wet cooling towers accomplish part of their cooling load by evaporating a part of the water supplied to them. Figure 3 expresses the fact that the water loss rate is proportional to the heat load on water-cooled condensers. Supercritical cycles have a higher cooling load than subcritical ones, because supercritical cycles produce more vapor to generate electricity and thus create higher heat load on condensers. Although water-cooled cycles yield a 1.32\%-5.43\% higher geofluid effectiveness and $62.10 \%-70.26 \%$ lower specific embodied energy consumption, in regions where water is scarce, the use of water-cooled cycles is still unacceptable. 
Table 7. Comparison of the air-cooled and water-cooled power plants.

\begin{tabular}{|c|c|c|c|c|c|c|c|}
\hline \multirow{2}{*}{$\begin{array}{c}T_{\text {gf-in, }} \\
{ }^{\circ} \mathrm{C}\end{array}$} & \multirow{2}{*}{$\begin{array}{c}\text { Power Plant } \\
\text { Type }\end{array}$} & \multicolumn{3}{|c|}{$\begin{array}{l}\text { Geofluid Effectiveness } G F_{e}, \\
\qquad \mathbf{k J} / \mathbf{k g}\end{array}$} & \multicolumn{3}{|c|}{$\begin{array}{c}\text { Power Plant Specific Embodied Energy } e b_{\mathrm{PP}} \text {, } \\
\text { TJ/MWe }\end{array}$} \\
\hline & & Air-cooled & Water-cooled & Increase, \% & Air-cooled & Water-cooled & Decrease, \% \\
\hline 200 & $\mathrm{SF}$ & 49.64 & 52.34 & 5.43 & 14.86 & 5.63 & 62.10 \\
\hline 200 & $\mathrm{DF}$ & 64.01 & 67.36 & 5.24 & 14.84 & 5.31 & 64.20 \\
\hline 300 & $\mathrm{SF}$ & 143.04 & 147.96 & 3.44 & 10.12 & 3.14 & 68.94 \\
\hline 300 & $\mathrm{DF}$ & 182.31 & 188.25 & 3.26 & 9.87 & 2.94 & 70.26 \\
\hline 400 & TENS & 781.36 & 794.63 & 1.70 & 4.66 & 1.58 & 66.02 \\
\hline 500 & TENS & 1021.10 & 1036.53 & 1.51 & 4.26 & 1.46 & 65.70 \\
\hline 600 & $\mathrm{DE}$ & 1180.24 & 1197.15 & 1.43 & 3.73 & 1.29 & 65.56 \\
\hline 700 & $\mathrm{DE}$ & 1330.59 & 1348.64 & 1.36 & 3.69 & 1.27 & 65.44 \\
\hline 800 & SE & 1455.73 & 1474.91 & 1.32 & 3.68 & 1.28 & 65.37 \\
\hline
\end{tabular}

Figure 3. Water-cooled plant cooling water loss rate with respect to $T_{\mathrm{gf}}$ in for different plant configurations. SF: single flash; DF: double flash; TENS: triple expansion without superheating; DE: double expansion; SE: single expansion.

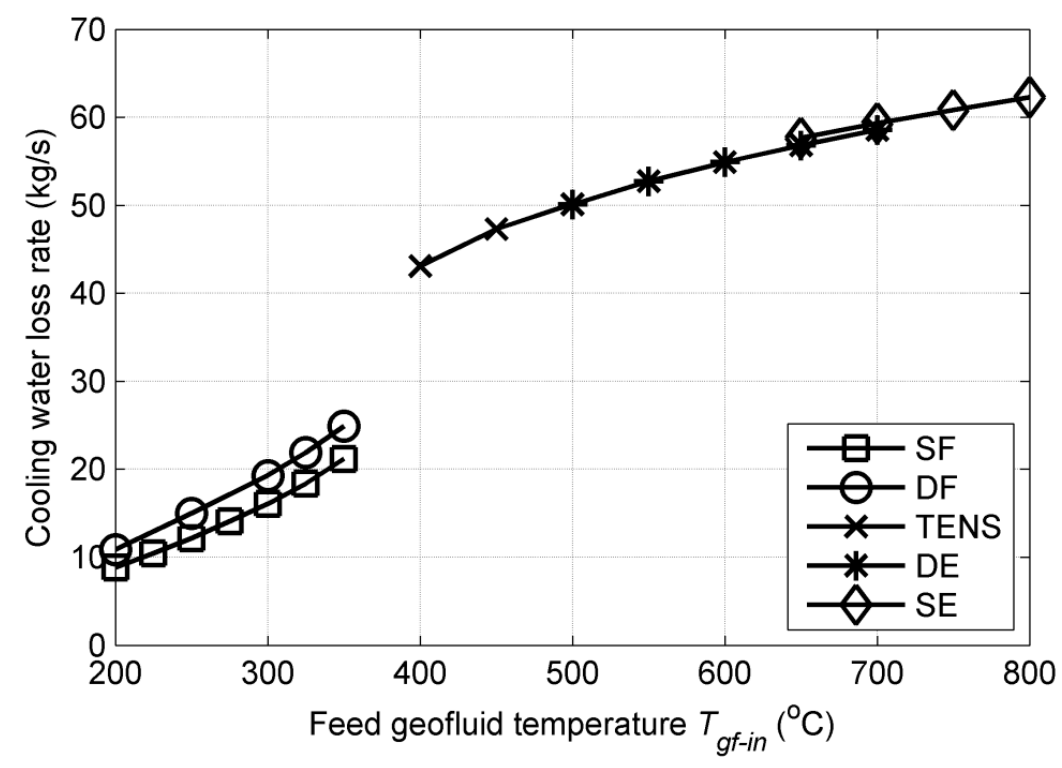

\section{Conclusions}

This paper presents a brief review of flash and expansion type of geothermal power plants and proposes, analyzes, examines, and compares leading geothermal power plant configurations focused on mid-high grade deep HDR resources where the geofluid temperature ranges from 200 to $800{ }^{\circ} \mathrm{C}$. Single-flash and double-flash cycles are studied for electricity generation using subcritical geofluid $\left(<374{ }^{\circ} \mathrm{C}\right)$ and triple-expansion, double-expansion and single-expansion cycles are chosen for using supercritical geofluid $\left(>374{ }^{\circ} \mathrm{C}\right)$. The simulation method is validated by comparison to published studies.

The results include the geofluid effectiveness, plant utilization efficiency, plant energy and exergy efficient, plant' embodied energy and specific embodied energy, all as a function of the fed geofluid temperature $T_{\mathrm{gf} \text { in }}$ in the range of $200-800{ }^{\circ} \mathrm{C}$. Flash type power plants have utilization efficiency ranging from $30 \%$ to $60 \%$ for geofluid temperature between 200 and $350{ }^{\circ} \mathrm{C}$ while expansion plants 
could achieve a utilization efficiency higher than $70 \%$ when fed with supercritical geofluid. The utilization efficiencies are around $70 \%$ for all supercritical fed geofluid temperatures. The energy efficiency of flash type plants ranges from $13 \%$ to $23 \%$ while ranges from $30 \%$ to $37 \%$ for expansion type plants. The exergy efficiency of flash type and expansion type plants are $40 \%$ to $55 \%$ and $70 \%$ to $75 \%$ respectively.

For supercritical feed geofluid, the analysis shows that lower geofluid feed pressure results in higher $G F_{e}$, so the geofluid pressure should be kept as low as possible as long as it is in supercritical state. To avoid steam expansion into the wet regime, and thus to protect the turbine blades, we investigated a configuration in which the steam is superheated by using the geofluid from the reservoir prior to its feed into the turbine. It was found that this reduces the $G F_{e}$ and net power output by around $28.3 \%$. Liquid reinjection temperature should be maintained to be larger than $60{ }^{\circ} \mathrm{C}$ to avoid mineral scaling in the injection wells. However, we found that single and double-expansion plants cannot satisfy this when the condensing temperature is $50{ }^{\circ} \mathrm{C}$ for geofluid fed temperature $>500{ }^{\circ} \mathrm{C}$. Raising the geofluid reinjection temperature reduces, however, the geofluid effectiveness $G F_{e}$, for example by $3.5 \%$ when the condensing temperature is raised to $60{ }^{\circ} \mathrm{C}$.

Comparison of air-cooled system with water-cooled system indicates that water-cooled systems could increase geofluid effectiveness $G F_{e}$ by $1.32 \%-5.43 \%$ and decrease the specific embodied energy by $62.10 \%-70.26 \%$.

Use of supercritical geofluid results in significant higher geofluid effectiveness $G F_{e}$ than use of subcritical geofluid, and the extent of this effect was evaluated. The specific power plant embodied energy is lower for supercritical plants. This supports the conclusion that EGS resource exploitation should aim at producing supercritical geofluid for the surface power plant.

\section{Author Contributions}

Guidance by Noam Lior, computations by Mengying Li, joint analysis.

\section{Nomenclature}

$\begin{array}{ll}d_{\text {in }} & \text { Absolute humidity of air feed to cooling tower, g/kg dry air } \\ E B \text { PP } & \text { Embodied energy of power plants, TJ } \\ e b_{\mathrm{PP}} & \text { Specific embodied energy of power plants, } \mathrm{TJ} / \mathrm{MWe} \\ \dot{E}_{\mathrm{gf} \_ \text {in }} & \text { Total exergy flux to the power plant, } \mathrm{kW} \\ e_{\mathrm{gf} \_ \text {in }} & \text { Specific exergy of the geofluid fed to the power plant, } \mathrm{kJ} / \mathrm{kg} \\ G F_{e} & \text { Geofluid effectiveness, } \mathrm{kJ} / \mathrm{kg} \\ M_{\mathrm{EQ}} & \text { Equipment weight of power plant, } \mathrm{kg} \\ \dot{m}_{\mathrm{gf} \_ \text {in }} & \text { Geofluid mass flow rate fed to the power plants, } \mathrm{kg} / \mathrm{s} \\ \dot{m}_{\mathrm{s} 1} & \text { Superheating geofluid flow rate, } \mathrm{kg} / \mathrm{s} \\ P_{0} & \text { Dead state pressure, Pa } \\ P_{\mathrm{cf} \_ \text {in }} & \text { Cooling fluid pressure feed to condenser, Pa } \\ P_{\text {cond }} & \text { Condensing pressure,Pa } \\ P_{\mathrm{FL}} & \text { Flashing pressure, } \mathrm{Pa} \\ P_{\mathrm{gf} \_ \text {in }} & \text { Feed geofluid pressure, Pa }\end{array}$


$P_{\text {gf_out }} \quad$ Geofluid pressure leave the power plant, $\mathrm{Pa}$

$T_{0} \quad$ Dead state temperature, $\mathrm{K}$

$T_{\text {cf_in }} \quad$ Cooling fluid temperature fed to the condenser, $\mathrm{K}$

$T_{\text {cond }} \quad$ Condensing temperature, $\mathrm{K}$

$T_{\mathrm{gf} \text { in }} \quad$ Geofluid temperature fed to power plants, $\mathrm{K}$

$T_{\text {gf_out }} \quad$ Geofluid temperature at power plants outlet (reinjection to reservoir), $\mathrm{K}$

$\dot{W}_{\text {cwp }} \quad$ Cooling water pump energy consumption, $\mathrm{kW}$

$\dot{W}_{\text {fan,cond }} \quad$ Air-cooled condenser fans energy consumption, $\mathrm{kW}$

$\dot{W}_{\text {fan,ctower }} \quad$ Cooling tower fans energy consumption, $\mathrm{kW}$

$\dot{W}_{\mathrm{gp}, i} \quad$ Geofluid pump energy consumption, $\mathrm{kW}$

$\dot{W}_{\text {net }} \quad$ Net work produced by the plant, $\mathrm{kW}$

$\dot{W}_{\text {parasitic }} \quad$ Total parasitic energy consumption, $\mathrm{kW}$

$\dot{W}_{\text {turbine }} \quad$ Total work produced by turbines, $\mathrm{kW}$

$\Delta \dot{E}_{\mathrm{gf}}$

$\Delta e_{\mathrm{gf}}$

$\Delta \dot{H}_{\mathrm{hf}}$

$\Delta h_{\mathrm{gf}}$

$\Delta P_{\text {cond }}$

Total exergy difference between the geofluid fed to and leaving the plant, $\mathrm{kW}$

Specific exergy difference between the geofluid fed to and leaving the plant, $\mathrm{kJ} / \mathrm{kg}$

Total enthalpy difference between the geofluid fed to and leaving the plant, $\mathrm{kW}$

$\Delta P_{\text {mix }}$

Specific enthalpy difference between the geofluid fed to and leaving the plant, $\mathrm{kJ} / \mathrm{kg}$

$\Delta T_{\mathrm{pp}}$

$\eta_{\mathrm{g}}$

Pressure drop in condenser, $\mathrm{Pa}$

Pressure difference of two mixing streams, $\mathrm{Pa}$

$\eta_{\mathrm{I}}$

Pinch point temperature difference in heat exchangers, $\mathrm{K}$

Generator efficiency

$\eta_{I I}$

Energy efficiency of power plants, $\%$

Exergy efficiency of power plants, $\%$

$\eta_{\text {II,pump }} \quad$ Pump Isentropic efficiency, \%

$\eta_{I I, t b} \quad$ Turbine Isentropic efficiency, $\%$

$\eta_{U} \quad$ Utilization efficiency of power plants, $\%$

\section{Abbreviations}

$\begin{array}{ll}\text { COND } & \text { Condenser } \\ \text { CS } & \text { Cyclone separator } \\ \text { DE } & \text { Double-expansion plant } \\ \text { DF } & \text { Double-flash plant } \\ \text { EGS } & \text { Enhanced/Engineered geothermal system } \\ \text { EROI } & \text { Energy return on investment } \\ \text { FL } & \text { Flasher } \\ \text { HDR } & \text { Hot dry rocks } \\ \text { HPT } & \text { High pressure turbine } \\ \text { HPT-SH } & \text { Super-heater before HPT } \\ \text { LPT } & \text { Low pressure turbine } \\ \text { LPT-SH } & \text { Super-heater before LPT } \\ \text { SE } & \text { Single-expansion plant }\end{array}$




$\begin{array}{ll}\text { SF } & \text { Single-flash plant } \\ \text { SPT } & \text { Super pressure turbine } \\ \text { TB } & \text { Turbine } \\ \text { TENS } & \text { Triple-expansion plant without superheating } \\ \text { TES } & \text { Triple-expansion plant with superheating } \\ T-S & \text { Temperature-entropy graph } \\ V F & \text { Vapor fraction }\end{array}$

\section{Conflicts of Interest}

The authors declare no conflict of interest.

\section{References}

1. The Future of Geothermal Energy: Impact of Enhanced Geothermal Systems (EGS) on the United States in the 21st Century: An Assessment by an MIT-led Interdisciplinary Panel; Massachusetts Institute of Technology (MIT): Cambridge, MA, USA, 2006.

2. DiPippo, R. Geothermal Power Plants: Principles, Applications and Case Studies; Elsevier: Amsterdam, The Netherlands, 2005.

3. Bertani, R. Geothermal power generation in the world 2005-2010 update report. Geothermics 2012, 41, 1-29.

4. Thorsteinsson, H.; Augustine, C.; Anderson, B.; Moore, M.; von Rohr, P.; Rothenfluh, T.; Tester, J. Sustainable Energy Opportunities Within the Geothermal Continuum; Clean Technology 2008; CSI Events: Danville, CA, USA, 2008; pp. 152-155.

5. Kruger, P.; Otte, C. Geothermal Energy, Resources, Production, Stimulation; Stanford University Press: Stanford, CA, USA, 1973.

6. Elliott, T.C.; Chen, K.; Swanekamp, R.C. Standard Handbook of Powerplant Engineering; McGraw Hill: New York, NY, USA, 1998.

7. Coskun, C.; Oktay, Z.; Dincer, I. Performance evaluations of a geothermal power plant. Appl. Therm. Eng. 2011, 31, 4074-4082.

8. Gerber, L.; Maréchal, F. Defining optimal configurations of geothermal systems using process design and process integration techniques. Appl. Therm. Eng. 2012, 43, 29-41.

9. Kanoglu, M.; Bolatturk, A. Performance and parametric investigation of a binary geothermal power plant by exergy. Renew. Energy 2008, 33, 2366-2374.

10. Yildirim, D.; Ozgener, L. Thermodynamics and exergoeconomic analysis of geothermal power plants. Renew. Sustain. Energy Rev. 2012, 16, 6438-6454.

11. Zhang, F.; Jiang, P. Thermodynamic analysis of a binary power cycle for different EGS geofluid temperatures. Appl. Therm. Eng. 2012, 48, 476-485.

12. Walraven, D.; Laenen, B.; D'Haeseleer, W. Comparison of thermodynamic cycles for power production from low-temperature geothermal heat sources. Energy Convers. Manag. 2013, 66, 2-14.

13. Augustine, C.R. Hydrothermal Spallation Drilling and Advanced Energy Conversion Technologies for Engineered Geothermal Systems. Ph.D. Thesis, Massachusetts Institute of Technology, Cambridge, MA, USA, June 2009. 
14. Dai, Y.; Wang, J.; Gao, L. Parametric optimization and comparative study of organic Rankine cycle (ORC) for low grade waste heat recovery. Energy Convers. Manag. 2009, 50, 576-582.

15. Franco, A.; Villani, M. Optimal design of binary cycle power plants for water-dominated, medium-temperature geothermal fields. Geothermics 2009, 38, 379-391.

16. Nguyen, T.Q.; Slawnwhite, J.D.; Boulama, K.G. Power generation from residual industrial heat. Energy Convers. Manag. 2010, 51, 2220-2229.

17. Yari, M. Exergetic analysis of various types of geothermal power plants. Renew. Energy 2010, 35, $112-121$.

18. Borsukiewicz-Gozdur, A.; Nowak, W. Maximising the working fluid flow as a way of increasing power output of geothermal power plant. Appl. Therm. Eng. 2007, 27, 2074-2078.

19. DiPippo, R. Ideal thermal efficiency for geothermal binary plants. Geothermics 2007, 36, 276-285.

20. DiPippo, R. Second law assessment of binary plants generating power from low-temperature geothermal fluids. Geothermics 2004, 33, 565-586.

21. Lee, K.C. Classification of geothermal resources by exergy. Geothermics 2001, 30, 431-442.

22. Barbacki, A. Classification of geothermal resources in Poland by exergy analysis - Comparative study. Renew. Sustain. Energy Rev. 2012, 16, 123-128.

23. Aspen Plus V7.3. Aspen Technology Inc. Available online: http://www.aspentech.com/products/ aspen-plus.aspx (accessed on 6 January 2012).

24. El-Emam, R.S.; Dincer, I. Exergy and exergoeconomic analyses and optimization of geothermal organic Rankine cycle. Appl. Therm. Eng. 2013, 59, 435-444.

25. Çengel, Y.A.; Boles, M.A. Thermodynamics: An Engineering Approach; McGraw-Hill series in mechanical engineering; McGraw-Hill Higher Education: Boston, MA, USA, 2006.

26. Hammond, G.; Jones, C. Inventory of Carbon \& Energy: ICE; Sustainable Energy Research Team, Department of Mechanical Engineering, University of Bath: Bath, UK, 2008.

27. Baumann, K. Some recent developments in large steam turbine practice. J. Inst. Electr. Eng. 1921, 59, 565-623.

28. Michaelides, E.E.; Ryder, J.K. The influence of seasonal and daily temperature fluctuations on the work produced by geothermal power plants. Int. J. Energy Syst. 1992, 12, 68-72.

29. Queiroz, J.A.; Rodrigues, V.; Matos, H.A.; Martins, F. Modeling of existing cooling towers in ASPEN PLUS using an equilibrium stage method. Energy Convers. Manag. 2012, 64, 473-481.

(C) 2014 by the authors; licensee MDPI, Basel, Switzerland. This article is an open access article distributed under the terms and conditions of the Creative Commons Attribution license (http://creativecommons.org/licenses/by/4.0/). 